\title{
David Canter: Forensic psychology-A very short introduction
}

\author{
Oxford University Press 2010, ISBN 978-0-19-955020-3
}

\author{
Claas T. Buschmann
}

Published online: 29 September 2010

(C) Springer Science+Business Media, LLC 2010

The "Very Short Introductions" book series published by Oxford University Press is designed to give general readers a fascinating and readily understandable account to complex subjects and will ultimately encompass around 300 titles. David Canter is Professor of Psychology at The University of Huddersfield/UK, and has a broad background and wide experience in forensic psychology teaching, research and practice. He now provides a small introduction to his discipline: The book is enjoyable and delightful to read, and the topics can easily be grasped and appreciated even by non-expert readers. It comprises 145 pages organized into 7 well-written and well-structured chapters ("The excitement and challenge of forensic psychology", "How to make a criminal", "Experts in court", "Psychology and legal proceedings", "Working with offenders", "Working with law enforcement", "Always the bridesmaid?") and is enriched with 14 black and white portraits of famous psychologists and photographs.

Focused topics are e. g. lie detection, offender profiling, jury selection, insanity in the law, predicting the risk of re-offending, and the minds of serial killers. The text includes possible explanations of criminal behavior and criminality, including the role of mental disorder in crime, and discusses how forensic psychology contributes to helping investigate the crime and catching the offenders. Considering the limitations inherent in a series of small-format books spanning a wide range of topics from history, philosophy, and religion to science, technology and medicine, the rapidly developing area of scientific psychology broadly known as Forensic Psychology is compromisingly covered, and the reader is held spellbound by references to popular movies ("Psycho", "No country for old men" etc.) as well as to spectacular crimes, e. g. the case of Fred and Rose West. Nevertheless, it may be worthwhile to consider adding some more case reports to forthcoming editions.

Several aspects of psychology - that are relevant to the legal and criminal process as a whole-are discussed, and the small book also explains how psychologists provide guidance to all those involved in civil and criminal court proceedings, including both the police and the accused, and what expert testimony can be provided by a psychologist about the offender at the trial. Finally, Professor Canter examines how forensic psychology is used, particularly in prisons, to help in the management, treatment and rehabilitation of offenders. The short but up-to-date reference list is a valuable tool for gathering further information.

To sum up, the author gives a valuable account of the challenges faced in forensic psychology. The book will give interested readers a deeper understanding and broad grasp of the complex field of forensic psychology.
C. T. Buschmann ( $\bowtie)$

Institute of Legal Medicine and Forensic Sciences, University

Medical Centre Charité-University of Berlin, Turmstr. 21,

Building L, 10559 Berlin, Germany

e-mail: claas.buschmann@charite.de

URL: http://remed.charite.de 